of the Tees it was possible to discriminate certain organisms as useful indicators of pollution.

The work opens up a number of questions, not only of economic importance but also of direct scientific interest. One of the most noteworthy points disclosed is our complete lack of knowledge concerning the life-histories of so many of those insects which form the major constituents in the food of trout and other fish. It was found impossible to identify many of the larval stages as these have never been described. The necessity for a comprehensive survey of this subject is stressed.

\title{
The Study of Genetics
}

$\mathrm{O}^{\mathrm{x}}$ three occasions recently the Indian jourmal Current Science has appeared as a special issue devoted to a particular topic. The third of these, dated March 1938, is devoted to genetics. It includes eight short reviews by acknowledged authorities, held together by an introduction by Dr. Eileen W. E. Macfarlane.

Dr. H. J. Muller writes on "The Present Status of the Mutation Theory", discussing the nature and the mode of action of the gene. The following section headings indicate the scope of his contribution : the gene as the material basis of mutation; the quantitative study of the normal mutation frequency; thermal and chemical influences on the mutation process ; the production of mutations by irradiation ; effects of mutations on the organism; changes in gene arrangement; and gene mutations as the primary steps of evolution.

Prof. O. Winge gives a very concise and clear review of the facts concerning the cytology of sex. He describes his own experiments on Lebistes in some detail in order to support his opinion that sex genes are present in all chromosomes and that there is always the possibility that the sex chromosome may become changed into an autosome and vice versa.

Prof. Kihara provides a short article on cytogenetics of species hybrids, whilst Dr. H. B. Frost, in an article on the genetics and cytology of citrus, furnishes a valuable example of the application of these disciplines to the study of a special group of economic value.

Special aspects of evolution are dealt with in the contributions by Prof. E. B. Babcock on phylogeny in the light of genetics and cytology and by Prof. A. F. Shull on adaptation in the light of genetics. The former stresses the importance of genetics, and particularly of comparative cytology, in discussions concerning phylogenetic relationships between groups of animals and plants, and illustrates his views with references to data from his and his co-workers' researches on the genus Crepis. Prof. Shull discusses the possible ways in which adaptation may have arisen through the interplay of mutation and selection, and suggests the lines which future work might profitably take when the problems of selection are being studied genetically.

Dr. C. B. Davenport in his "Genetics of Human Inter-racial Hybrids" stresses the importance of studies of this kind in regions where hybridization is just beginning, so that the first and second hybrid generations may be definitely known. He suggests that the regions where such studies might be profitably made are the Amoor River region in Siberia where the Siberians are coming into contact with the Japanese, in certain regions in Africa where the whites are meeting the practically full-blooded Negro stock, and in North America where the Eskimo and the white are now newly meeting.

The final article is by Dr. C. B. Bridges, who discusses in a most attractive way the future of genetics.
He is of opinion that the near future will see genetical studies extended to an ever-increasing number of animal and plant forms ; the intensive study of such forms as have so far failed to conform to established genetic principles, such studies leading to the consequent extension of those principles and to the invention of new hypotheses and the simplification of the old; the elaboration of new technical methods in genetic experimentation and in cytology; the employment of further physical or chemical and environmental agencies in the induction of cytogenetic novelty; the hybridization of genetics and cytology with other sciences such as chemistry, embryology, physiology ; and finally, the progressive clarification of man's philosophical outlook as to his origin, development and actjvities, with the rescue of still other departments of life from the deistic and vitalistic to the naturalistic and mechanistic realms.

Dr. Bridges recommends studies of bacteria and viruses and phages for an understanding of gene action and of the nature of sex, and points out that the gene now occupies for us the place held by the cell for a previous generation of biologists. The gene must be analysed in terms of its physical structure and chemical behaviour. For the moment we think of it as a crystalline body, probably of the fibre type, the autocatalytic growth of which is by surface con. densation of constituent simpler materials from the surrounding medium, and its reproduction is pictured as a simple split of this fibrous crystal when its growth has exceeded the size limits proper to its internal bonding versus the disruption due to temperature and other environmental factors. The model of gene structure must allow not only of autocatalytic growth and self-reproduction, but also of compositional change and the subsequent perpetuation of that new structure. On the hypothesis that the fields of force on the surface of the gene control its crystalline growth, it is conceivable that rare acceptance of a misfit building block would alter the surface material. The interpretation of 'position effects' will probably follow the idea that the action of the gene is limited by materials which diffuse into it. The induction of changes in the gene and in the chromosome by the use of radiations and of chemical agents is now only just begun. By their extended use, problems of the size, number, structure, mutability and action of the gene have become soluble. The cytologists may be expected to continue and elaborate their studies of the salivary gland chromosomes, and will proceed intensively to study the phenomena involved in the synapsis, crossing-over and distribution of chromosomes to the gametes.

Reading these articles, one cannot but be impressed by the extraordinary activity that is everywhere present in the field of genetics, by the luxuriance of its growth, and especially by its promise of great adventure. 